\title{
O EXERCÍCIO PROFISSIONAL DO/A ASSISTENTE SOCIAL EM CAPS: SUStentar um trabalho antimanicomial e emancipador ${ }^{*}$
}

\author{
Fernanda de Oliveira Monteiro \\ Wanessa Gonzaga de Oliveira
}

\section{Introdução}

Esse trabalho tem como objetivo discutir como se constitui a intervenção do Serviço Social em Centros de Atenção Psicossocial (CAPS), que são dispositivos de saúde mental tão caros no processo de reforma psiquiátrica brasileira.

Propõe além de apontar e refletir as atribuições dos assistentes sociais nesses dispositivos, contribuir para pensar os desafios postos na atualidade a esta profissional, na direção de um trabalho que articule os princípios da reforma psiquiátrica com os valores do projeto ético profissional visando à emancipação dos sujeitos em sofrimento mental.

Trata-se de um esforço de reflexão e sistematização do trabalho realizado pelas autoras em suas experiências em CAPS ao longo das suas trajetórias profissionais na atenção psicossocial tanto no campo dos transtornos mentais como de álcool e outras drogas.

Para tanto, recorreremos para análise deste capítulo a autores como Iamamoto (2005), Netto (2004), Vasconcelos (2008; 2009), Lúcia Rosa (2009), Paulo Amarante (2003; 2007), dentre outros para melhor embasar as discussões.

Inicialmente faremos uma breve retomada histórica da constituição das bases do movimento da reforma psiquiátrica brasileira pautada na lógica da atenção psicossocial e da desinstitucionalização dos usuários em sofrimento mental. Posteriormente, discutiremos as ações desenvolvidas pelas assistentes sociais em CAPS, articulando com o cenário político, econômico e social na atualidade. E por fim, buscaremos apontar alguns desafios e potencialidades para a direção do trabalho numa perspectiva emancipatória e antimanicomial.

\section{O trabalho dos assistentes sociais nos CAPS na lógica da atenção psicossocial}

\subsection{Trajetória da construção da política de saúde mental no Brasil}

O processo de reforma psiquiátrica brasileiro iniciou-se na década de 1970, contemporâneo ao Movimento de Reforma Sanitária, que buscava novos modelos de atenção, de gestão de saúde, de participação da sociedade - usuários, trabalhadores e familiares na construção do cuidado em saúde. Possui uma construção singular inspirada nos Movimentos de Reforma Psiquiátrica ocorridos no mundo que buscavam superar a violência ocorrida nos asilos psiquiátricos. Contudo, a maior influência foi da Psiquiatria Democrática Italiana, baseada na desinstitucionalização dos asilados.

${ }^{*}$ DOI- 10.29388/978-65-81417-27-7-0-f.93-107 
Cabe ressaltar que a desinstitucionalização transcende a função de retirar os sujeitos dos hospitais psiquiátricos, envolve a modificação dos padrões de segregação presentes nestes espaços e busca "novas maneiras de ser, reinventar novas formas de viver e, no âmbito do cuidado com a saúde mental, criar novas abordagens, praticar novos olhares, inventar a mudança para influir de forma positiva na determinação social do processo saúde-doença" (MILLANI e VALENTE, 2008, p.11).

Amarante (2003) destaca três principais vertentes de reforma psiquiátrica no mundo: a perspectiva do hospital reformado, a partir da Psicoterapia Institucional, que propunha mudanças na estrutura hospitalar e na composição das equipes, mas mantinha o asilo psiquiátrico como lugar de cuidado; a Psiquiatria de Setor e Psiquiatria Preventiva, que tinha na comunidade a base do tratamento, mas ainda utilizava-se do hospital e da internação; nela o hospital seria dividido em setores como a comunidade que o usuário fazia parte; e, por último, a Antipsiquiatria Inglesa e a Psiquiatria Democrática Italiana que faziam parte da perspectiva que questionava a razão psiquiátrica, a instituição hospitalar e propunha a sua extinção.

Para todas estas perspectivas, era legítimo o questionamento da função terapêutica dos asilos psiquiátricos, que muito embora na sua criação, institucionalizou o tratamento à loucura, reconhecendo um direito a tratamento que antes inexistia (TENÓRIO, 2001), ao longo do tempo, estes perderam seu mandado terapêutico (DELGADO, 1992), pois isolaram os ditos loucos, principalmente para os internos de longa permanência, provocando a perda de suas referências pessoais e sociais e um processo de deculturação dos mesmos (GOFFMAN, 1961).

Nesta mesma época, o Brasil vivia sob regime político da ditadura militar desde o golpe instaurado em 1964 e diversos setores da sociedade questionavam não apenas este regime político que limitava direitos constitucionais basilares como direitos civis e políticos, mas também a profunda desigualdade de condições de vida e de acesso a direitos sociais básicos, como: saúde, educação e saneamento básico.

A restrição de direitos imposta pelos militares ensejou movimentos de resistência que se ampliaram para a luta dos direitos citados anteriormente, e também, produziu questionamentos sobre acesso a direitos sociais de forma ampla e irrestrita.

Isso também reverberou nos asilos psiquiátricos que foram até a promulgação da Lei 10.216 em 2001, a principal política de Estado ofertada para as pessoas em sofrimento mental. Estes por sua vez serviram, historicamente, não apenas ao tratamento aos sujeitos citados, mas também para abordagem a todo e qualquer comportamento considerado desviante na sociedade, num "modus operandi”" de higienização social.

No Brasil, a metodologia de tratamento ao dito doente mental sofreu transformações importantes, anos antes, com o trabalho desenvolvido pela Dra Nise da Silveira, no Hospital Psiquiátrico Pedro II, no Engenho de Dentro, ainda na primeira metade do século XX, em 1946. Baseada na arterapia e na constituição das equipes de tratamento com outras categorias profissionais para além de médicos e profissionais da enfermagem. Nise da Silveira protagonizou, no Brasil o início de um trabalho com equipe multiprofissional, ampliando a análise e o cuidado sobre sofrimento psíquico, além do binômio saúde-doença em relação ao sujeito. Seu trabalho baseava-se em oficinas abertas de atividades ocupacionais, profissionalizantes e artísticoexpressivas, priorizando a clientela grave de instituições asilares psiquiátricas públicas (VASCONCELOS, 2008). 
$\mathrm{Na}$ década de 1980, importantes movimentos que resultaram da articulação de profissionais e familiares de usuários de saúde mental construíram de forma coletiva agendas de discussão através do Encontro de Bauru, em 1987 que delineou pontos cruciais para o avanço do Movimento da Reforma Psiquiátrica brasileiro.

No Estado do Rio de Janeiro, ainda nesta época, ações de apoio à desinstitucionalização foram de extrema importância e vanguarda como a criação das primeiras associações de usuários, familiares e profissionais de saúde mental, em Angra dos Reis, a criação do primeiro serviço substitutivo também naquele município; a intervenção na Casa de Saúde Dr Eiras em Paracambi e a desativação do Hospital Colônia Teixeira Brandão no Carmo, Região Serrana, além da criação dos Serviços Residenciais Terapêuticos (BRASIL, 2005). Nesta arena de disputas, com avanços e recuos, a Lei da Reforma Psiquiátrica, Lei 10.216 foi promulgada em 2001, com alguns vetos no texto original que era de 1989 e ficou conhecida como Lei Paulo Delgado, em homenagem ao deputado petista, autor do projeto de lei.

Mesmo antes da existência da lei, muitos serviços de base comunitária já funcionavam inspirados nos Centos Diários de Atenção a Saúde Mental, de experiência italiana. Em SantosSP, no fim da década de 1980, em Angra dos Reis-RJ no início dos anos de 1990, foram as primeiras experiências que, posteriormente se ampliaram para outros lugares. No Estado do Rio de Janeiro, por exemplo, até o ano 2000 existiam cerca de 50 CAPS e, no Brasil entre 1980 a 2000, existiam 208 (BRASIL, 2007). Embora houvesse a previsão de financiamento dos mesmos pela Portaria SAS-MS 224 de 1992, cerca de 93\% dos recursos do Ministério da Saúde para a Saúde Mental, ainda são destinados aos hospitais psiquiátricos.

Neste sentido, o processo da Reforma Psiquiátrica brasileira é maior do que a sanção de novas leis e normas e maior do que o conjunto de mudanças nas políticas governamentais e nos serviços de saúde e inseria-se num contexto internacional que buscava superar a violência asilar, a crise do modelo de assistência centrado no hospital psiquiátrico, por um lado, e na eclosão, por outro, dos esforços dos movimentos sociais pelos direitos dos pacientes psiquiátricos (BRASIL, 2007a). Contudo, o maior avanço na desinstitucionalização e da criação dos serviços de atenção diária em saúde mental se deu a partir da lei da reforma psiquiátrica e das normativas na área que impulsionaram e financiaram a criação dos serviços substitutivos, que teve como estratégia prioritária os Centros de Atenção Psicossocial.

Pode-se afirmar que até a metade da segunda década do presente século, a política de saúde mental brasileira avançou progressivamente na consolidação dos direitos das pessoas em sofrimento mental, combatendo as internações especializadas de longa permanência, fechando manicômios e revertendo o investimento de verba pública que antes eram aplicados exclusivamente nestes espaços para incentivar, construir e consolidar espaços de acolhimento e tratamento territoriais, abertos e democráticos, como os CAPS em suas diversas modalidades, as residências terapêuticas e os leitos de internação em hospitais gerais ou enfermarias especializadas em hospitais gerais, dentre outros.

Também consolidou espaços de discussão através de encontros, fóruns, conferências, congressos nas diferentes esferas de gestão de políticas onde o principal interessado - usuários e familiares da saúde mental - estava presente em sua voz, principalmente do usuário era respeitada e suas opiniões consideradas para construção coletiva das políticas públicas que seriam destinadas a eles mesmos.

Avançou ainda na construção de estratégias de desinstitucionalização de pessoas que viveram e sobreviveram aos períodos de longa internação, com modalidades de serviços de 
moradia como as residências terapêuticas, possibilitando aos usuários da saúde mental ter seu direito constitucional à moradia e de ir e vir garantidos.

No campo da atenção aos usuários de álcool e outras drogas embates e discussões sobre abordagem a álcool e drogas ocorreram, havendo um entendimento que a Política de atendimento a este público deveria ser baseada na perspectiva da Redução de danos e do cuidado do território, sendo o CAPS AD um dos protagonistas quando se pensa na articulação do cuidado.

Todas essas mudanças, alicerçadas num conceito ampliado de saúde que envolve condições de vida, de trabalho, de lazer, de estar no mundo, para além dos aspectos biológicos fortalece a importância de outras categorias profissionais no cuidado ao sujeito em sofrimento mental, dentre estas a categoria das assistentes sociais, como profissão que a partir das dimensões de sua atuação profissional, teórico-metodológica, ético-política e técnico - operativa tem a competência de compreender de que forma as diferentes expressões da Questão Social incidem no quadro de saúde mental do sujeito e de sua família, e como articular as diferentes políticas públicas, serviços e programas para atender às demandas que surgem no cotidiano dos espaços de atuação profissional.

Nos últimos cinco anos, após mudanças na direção nacional na política de saúde mental devido à ascensão ao poder de partidos conservadores, a arena de disputa tornou-se mais tensa e o movimento conservador e antidemocrático avançou. Com isso novas aberturas à perspectiva manicomial revestidas de nova roupagem ocorreram, tais como o retorno do investimento em leitos de hospital especializado, o financiamento às comunidades terapêuticas, presentes na proposta da Nota Técnica n¹1/2019.

Pelo texto da referida nota, todos os serviços, que compõem a Rede de Atenção Psicossocial (RAPS), são igualmente importantes e devem ser incentivados, ampliados e fortalecidos. E o Ministério da Saúde não considera mais serviços substitutos de outros, não fomentando mais fechamento de unidades de qualquer natureza. Continua afirmando que a Rede deve ser harmônica e complementar e que não há mais porque se falar em "rede substitutiva", já que nenhum serviço substitui outro. Conclui o trecho sinalizando que o país necessita de mais e diversificados tipos de serviços para a oferta de tratamento adequado aos pacientes e seus familiares. O que de interessante pode-se destacar da nota é a possibilidade de financiamento de serviços de Ambulatórios Multiprofissionais de Saúde Mental, o que atende a realidade de inúmeros municípios com menos de 20 mil habitantes que não conseguiram credenciar CAPS, conforme as normativas que determinam este processo (BRASIL, 2019)

Contudo, considera-se de modo global tratar-se de um retrocesso, que admite novamente redirecionar investimento às instituições fechadas, numa realidade em que os paradigmas manicomial e de atenção psicossocial disputam cotidianamente espaço e que o último, que busca incessantemente garantir direitos de cidadania aos sujeitos com sofrimento psiquiátrico tem ameaçada sua prioridade estratégica de investimento e de gestão de cuidado como orientação da política nacional de saúde mental.

Em nossa realidade, com as sucessivas crises econômicas, próprias do ciclo capitalista de ápice e de estagnação do crescimento econômico, acompanhadas de um investimento descontinuado em políticas de redistribuição de renda e de combate às desigualdades sociais, 
trazem alguns embates e debates a tona nesta transição da segunda para a terceira década do século XXI, que também traz consigo a Pandemia da Covid $19^{1}$.

Neste sentido, a letalidade do vírus, as medidas de prevenção e cuidado necessárias, o não investimento em políticas de saúde, educação e pesquisa, associados à desigualdade social que não foi combatida a contento, resultaram em quase 500 mil vítimas já neste fim do primeiro semestre de 2021. As medidas de isolamento social, o desemprego e as preocupações sobre como será o futuro e se ele vai existir, são alguns dos desafios de trabalho contemporâneos que se refletem também na política de saúde mental uma vez que aumenta a demanda de atendimento na área e agrava quadros de sofrimento psíquico e socioeconômicos da população, público alvo da rede de serviços psicossociais, trazendo novos demandas.

\subsection{Reflexões sobre as ações do Serviço social em CAPS}

Diante deste contexto tão aviltante, engendrado tanto pela radicalização da implementação do projeto neoliberal no país, por sua defesa pela redução do Estado provedor, por um Estado Mínimo para os direitos, e, por fim, a transferência da responsabilidade do Estado para a família e para a comunidade, quanto às ações e serviços, o Serviço Social encontra vários desafios enquanto profissão, posto que a realidade não se constitui enquanto mero pano de fundo, mas traz influência direta na vida da população usuária, nas políticas sociais, bem como, na própria situação da assistente social enquanto trabalhador assalariado (IAMAMOTO, 2005).

Além disso, a conjuntura social, política e economia tensiona na constituição de novas roupagens da questão social que é o objeto de trabalho do Serviço Social. Essas novas roupagens se expressam na saúde mental nos diversos tipos de adoecimento psíquico na atualidade, no suicídio, nas diversas expressões de violência, dentre outros.

Pensando especificamente no papel da assistente social nos CAPS, a partir das nossas experiências, podemos afirmar que este se constitui numa tentativa incessante e contínua de materializar os princípios do Código de Ética profissional (1993), a partir da interlocução com os pressupostos na Reforma Psiquiátrica brasileira. Dito de modo mais direto é tentar construir na cotidianidade do serviço, práticas que defendam os direitos dos usuários com transtornos mentais no usufruto do espaço público, da convivência familiar e comunitária, no acesso aos demais serviços e políticas, conforme a realidade social e demanda singular destes sujeitos, e nos respeitos aos seus direitos humanos.

São velhas e novas demandas que se põem ao trabalho da assistente social nos CAPS no que tange à dimensão técnico-operativa da profissão. Machado (2009) identifica dentre as velhas demandas a acolhida, orientação previdenciária, abordagem familiar em grupo e individual, acionar recursos e rede social, alta social e visita domiciliar para as quais a profissão foi historicamente requisitada. E dentre as novas, orientação e encaminhamento a direitos sociais, trabalho intersetorial, técnico de referência, geração de renda, oficina de artes, oficinas de cidadania e gestão e coordenação de CAPS. Nas próximas linhas, trataremos especificamente de alguns pontos de articulação entre velhas e novas demandas na realidade cotidiana de um CAPS

\footnotetext{
1 "A ocorrência da COVID-19 causada por uma nova cepa de coronavírus (Sars-CoV-2) foi relatada pela primeira vez na cidade de Wuhan, na China, em dezembro de 2019. Em 30 de janeiro de 2020, a Organização Mundial da Saúde (OMS) declarou o surto de COVID-19 como uma emergência de saúde pública de interesse internacional, e em menos de três meses a doença se espalhou pelo mundo, sendo declarada uma pandemia em 11 de março de 2020" (ALMEIDA, 2020, p.23).
} 
e o papel estratégico de nossa profissão na construção deste cuidado diário de desinstitucionalização.

Isso pode ser observado quando se requisita, por exemplo, o benefício da prestação continuada (BPC-LOAS) para usuário que nunca teve acesso à renda em que o sujeito tem determinado valor a partir dessa possibilidade de consumir bens e desta garantia de renda via BPC, possibilita suprir suas necessidades.

Como exemplo, podemos citar a experiência diante de um caso de um usuário que num intervalo de dez (10) anos havia passado por cinquenta (50) internações psiquiátricas. Ao analisar o histórico das internações psiquiátricas obtidas por meio das declarações das instituições, pudemos identificar que o mesmo passava períodos de aproximadamente dois ou três dias em casa, e logo retornava para nova internação. É possível identificar também, ausência de acesso à condições de moradia, precário ou inexistente suporte em saúde e saúde mental no seu território, vulnerabilidade socioeconômica que negava seu acesso ao básico como alimentação, ausência de referências familiares em condições de auxiliá-lo em suas atividades de vida diária e a própria vinculação social no território faziam que esse processo sempre se repetisse.

A partir do trabalho da assistente social foi possível a retirada de todos os documentos, direito civil a que o usuário não tinha acesso há muito tempo, e posteriormente, orientação a direitos sociais e requisição do BPC /LOAS, a fim de garantir renda e consequentemente garantir sua subsistência. Entretanto, consolidar um trabalho de desinstitucionalização requeria ir além, através de uma concomitante articulação para um trabalho intersetorial entre as diferentes políticas públicas que a realidade singular desse usuário exigia. Então, iniciou-se um processo de discussão do caso com a rede da assistência social no sentido de garantir que, junto com cuidado promovido pelo CAPS numa espécie também de matriciamento, esse usuário permanecesse temporariamente em acolhimento na Casa de Passagem, a fim de interromper o ciclo de exposição a vulnerabilidade e risco explicitado anteriormente.

Foi realizado ainda, um levantamento da demanda dos usuários de saúde mental, em atendimento no CAPS, que viviam com condições restritas de autonomia (TIKANORY, 1996), sem vínculo familiar, ou com vínculos rompidos e propôs-se um projeto de moradia assistida vinculado à saúde mental já que o município não tinha perfil para a estruturação de um serviço residencial terapêutico. A partir da estruturação deste dispositivo, que buscava seguir o modelo das residências terapêuticas, contudo, mantido exclusivamente com recurso municipal, com doações de munícipes - familiares de usuários e por profissionais, o usuário foi encaminhado para a Moradia Assistida após algumas reinternações e períodos de idas e vindas do hospital psiquiátrico para Casa de Passagem.

A criação deste dispositivo e a inserção de usuários com perfil semelhante, exceto no número de internações, trouxe-nos desafios, posto que foi necessário reorganizar o trabalho e o Serviço Social esteve (está) diretamente envolvido, no sentido de construção de uma nova forma de estar em sociedade na qual vários aspectos básicos da vida diária como ir ao supermercado fazer compras, o acompanhamento para escolher/comprar seu vestuário, recebimento e orientação sobre administração de sua renda, dentre outras passaram a ser trabalhados.

Como resultado deste trabalho observa-se que este usuário vem construindo maior autonomia, é acompanhado no CAPS de forma regular, obteve estabilização do seu quadro clínico que apresenta várias comorbidades orgânicas, e encontra-se há seis anos sem novas internações em um hospital psiquiátrico. 
O relato deste caso vivenciado por nós é uma forma de socializar o entendimento de que o trabalho na saúde mental, principalmente da assistente social, não está apenas embasado em discursos politicamente corretos em prol da reforma psiquiátrica e da luta antimanicomial, mas requer engajamento diário, prática de desconstrução cotidiana do modelo psiquiátrico manicomial que vive em nós, já que fazemos parte dessa sociedade em que se exclui os diferentes, desrespeita os desiguais e que ainda, apesar de muitos avanços, entende que lugar do louco é no hospício, ou na atualidade, os CAPS lhe negando o direito à circulação na cidade e à convivência comunitária, ou ainda, numa tentativa de limitar sua circulação ao CAPS, enquanto institucionalização no próprio serviço de atenção diária.

Trata-se de uma necessária articulação das dimensões ético-políticas embasadas nos pressupostos de nossa profissão por meio do projeto ético político profissional majoritariamente defendido, nos pressupostos do paradigma da desinstitucionalização, a partir do conhecimento do campo de intervenção profissional e das disputas e tensões existentes neste para, pôr em prática, a dimensão técnico-interventiva que garanta acesso a direitos civis, sociais e humanos.

Outra ação realizada pelo Serviço Social em CAPS é o encaminhamento e o acompanhamento para referenciamento aos dispositivos e serviços de proteção social básica como os CRAS (Centro Referência de Assistência Social) e serviços de convivência familiar e comunitária, para acesso a programas de transferência de renda, aluguel social, cesta básica emergencial, dentre outros. Bem como, aos serviços de proteção social especial de média complexidade como CREAS (Centro de Referência Especializado de Assistência Social) e aos serviços de proteção social especial de alta complexidade, naqueles casos em que há fragilidade dos vínculos familiares ou rompimento destes.

Não são poucas as situações que lidamos no cotidiano de trabalho em que usuário sofre algum tipo de violência doméstica e cabe ao Serviço Social e também aos outros profissionais, a notificação da violência às autoridades específicas, assim como, o encaminhamento para referenciamento e acompanhamento no CREAS e no serviço especializado de atenção a famílias e indivíduos (PAEFI). É importante esclarecer que não se trata de um encaminhamento no sentido de transferir a demanda para outro dispositivo, mas sim o compartilhamento dos atendimentos, onde cada instituição em sua especificidade, por meio de discussão desses casos, devem pensar conjuntamente com a rede de serviços, as ações que serão pactuadas no sentido de garantir os direitos dos usuários e interromper a violação de direitos vivenciada.

Cabe ressaltar que não se trata, porém de um processo simples, posto que por diversas vezes, deparamo-nos com dificuldades, sobretudo, porque nos defrontamos com profissionais que entendem que o usuário com transtorno mental é incapaz de cuidar dos filhos, de gerir sua própria vida ou de responsabilizar-se por seus atos. Tal posicionamento está embasado no estigma da questão da doença mental que fora construído socialmente e culturalmente. Embora, não seja atribuição especifica da assistente social é também uma das ações protagonizadas por nossa profissão, através do diálogo e da corresponsabilização, debatermos a dimensão cultural e social da loucura (AMARANTE, 2007) no sentido de desconstruir tais concepções, uma vez que estas interferem no acesso do usuário da saúde mental ao serviços e políticas sociais de forma equânime e integral. Não raro, deparamo-nos com profissionais que questionam o direito dos usuários de saúde mental de acessar dispositivos de outras políticas, e de circulação livre no território que ele tem como referência, como por exemplo, os que vivem em situação de rua e possuem sofrimento psiquiátrico grave ou em outra situação de risco social. 
O trabalho com famílias também é uma das ações do Serviço Social na realidade dos CAPS, que presta orientação a familiares, através de grupos de familiares ou de atendimentos individuais, no que tange ao esclarecimento sobre o processo saúde-doença, desconstrução de estigmas e orientação sobre direitos dos usuários e seus familiares. Contudo precisamos ficar atentos porque não cabe a nós julgar essas famílias ou tentar enquadrá-las em modelos que são desejáveis, mas entender que a família em seus diversos arranjos, também sofre devido a situação do usuário, bem como, vivenciam as consequências de um modelo embasado no projeto neoliberal de desresponsabilização do Estado e de transferência de funções de proteção social que seriam deste para as famílias, culpabilizando estas pelos problemas enfrentados por seus membros (ROSA, 2008). Colocar-nos enquanto parceiros e pensarmos conjuntamente no bemestar e na garantia do direito dos usuários e de suas famílias é de extrema relevância, não os entendendo apenas como meros demandatários de cuidados, mas como sujeitos de direito.

Outro aspecto presente no trabalho desta profissional é a defesa de estratégias de cuidado aos usuários com transtornos mentais junto à equipe multiprofissional no território para que apenas em último caso, ou seja, quando todas as medidas extra-hospitalares forem, de fato tentadas, se pensar na internação de um usuário em hospitais psiquiátricos. Isso, porém só é possível como empenho no sentido de uma busca de cuidado no território, a pactuação de um projeto terapêutico singular em articulação com outros atores como a Estratégia Saúde Da Família de referência, com o serviço de saúde de urgência/emergência, com a família, com os usuários e com os dispositivos assistenciais que tiverem relacionados com cada caso como CRAS, CREAS, CASA DE PASSAGEM, Acolhimento Infantil, Acolhimento de mulheres vítimas de violência doméstica, dentre outros.

Pensar na internação psiquiátrica como último recurso não é tarefa fácil, mas continua sendo tarefa necessária a fim de combater a cultura manicomial que persiste e que lamentavelmente, por vezes sai fortalecida devido a precarização de funcionamento de diversos pontos de atenção da rede de cuidados, o que promove assistência insuficiente e expõe o usuário e a família em suas próprias necessidades. São nestas brechas, que as práticas e discursos manicomiais ganham força no dia a dia. Assim sendo, pensar intersetorialmente o cuidado e de forma integral com responsabilidade de todos os entes é um tensionamento frequente a ser provocado, ultrapassando o discurso comum de que existe lugar definido para o usuário da saúde mental, ou de que esse "usuário é de tal lugar".

Ou seja, trata-se de explorar o máximo das possibilidades do cuidado, sem deixar-se sucumbir ou optar pelo que, talvez seja uma decisão mais cômoda, como a internação deste usuário, em um local que expressa um modelo de restrição de liberdade, isolamento, negação de identidade e afastamento do território, como é o caso dos hospitais psiquiátricos.

Ainda no que tange às novas demandas, podemos citar outra ação desenvolvida pela assistente social que são as assembleias de usuários, onde a profissional auxilia na organização e condução, media o debate, por meio de seu arcabouço teórico metodológico e ético político. A assembleia se constitui numa possibilidade de ação nos dispositivos em Saúde Mental que tem como pressuposto ser um espaço de diálogo e de decisão conjunta quanto à forma de funcionamento dos serviços (organização, modos de se relacionar, oficinas ofertadas), assim como, em questões que o extrapolam, mas tem relação com este. A participação da assistente social nessa ação possibilita esclarecimento sobre os direitos dos usuários e seus familiares, bem como a defesa de que esse espaço seja utilizado enquanto lugar de participação de todos, e não como um instrumento de manutenção do que está dado, como uma atividade para ocupar o 
tempo na rotina institucional, mas que de fato seja reafirmada como forma de participação democrática dos envolvidos e num mecanismo de controle social.

\subsection{Especificidade do trabalho da atenção psicossocoial no campo de álcool e outras drogas}

De modo geral, a dimensão operativa do trabalho das assistentes sociais em CAPS I tem estreita semelhança com as atividades realizadas em Caps Ad, porém existem especificidades em decorrência da diferença entre a conformação do cuidado nos casos de usuários que fazem uso abusivo de álcool e outras drogas em relação aos casos de transtornos mentais.

Em ambos os casos, muitas vezes o primeiro atendimento é realizado com a família. Contudo, nos casos dos sujeitos com transtorno mental a intervenção quase sempre sendo direcionada para explicar o objetivo do CAPS, de fortalecimento do cuidado no território e no sentido de reverter a intenção de uma internação psiquiátrica. Em geral, as famílias chegam ao dispositivo com sentimentos muito ambivalentes e querem internar os seus e resistentes a tentativas que explorem ao máximo o tratamento no território - possibilidade esta que é muito mais qualitativa e considera os direitos constitucionais dos usuários.

O campo da clínica de álcool e drogas também perpassa pela desmistificação da internação como único tratamento possível que teria algum resultado; as famílias em geral acreditam, ou são levadas, pelas circunstâncias, a crerem na internação em comunidade terapêutica ou clínica de recuperação como meio exclusivo e eficaz de tratamento para este usuário. Nesse atendimento inicial, em geral se apresenta um entendimento familiar, alicerçado a partir da conformação social e histórica deste sujeito, que faz uso prejudicial de álcool e outras drogas, como um criminoso ou como alguém que não tem caráter ou não tem força de vontade.

Deste modo, a orientação ao sujeito e à família perpassa por esclarecer que se trata de uma questão de saúde pública e não de algo determinado moralmente e que o usuário necessita de um suporte da equipe multiprofissional, bem como de estar em seu território, com seus vínculos familiares preservados, quando possível, contando com o suporte de uma rede socioassistencial e de saúde que possa pensar no cuidado que será a ele ofertado.

Historicamente, a política de álcool e outras drogas, no Brasil teve sempre um caráter punitivo-moralista, baseado no princípio da abstinência e da guerra às drogas tanto que não estava atrelado ao Ministério da Saúde e sim, ao Ministério da Justiça. Outra evidencia disto é que se denominava como uma Política Nacional Antidrogas e as campanhas deixavam muito explícito esse cunho como, por exemplo, o "crack é preciso vencer", numa perspectiva de negação da própria utilização de substâncias psicoativas pelos homens e sociedade em geral ao longo de toda a história da humanidade.

Apenas em 2005, o Brasil passa adotar a Política Nacional sobre Drogas havendo então uma substituição da nomenclatura. Mas não foi apenas isso, e o entendimento de que existe de fato, a necessidade de certo enfrentamento sobre a questão da repressão ao tráfico de drogas que dialoga nesta mesma política com a perspectiva do cuidado em saúde, da compreensão do uso abusivo de álcool e outras drogas como uma questão de saúde pública, na perspectiva da redução de danos e não mais da abstinência.

Do ponto de vista prático, esse atendimento está estruturado, tanto dentro dos CAPS $\mathrm{AD}$ ou dos CAPS I, neste último caso, em municípios que não tem perfil populacional para o primeiro dispositivo, de modo que esse sujeito e sua família sejam acolhidos no sentido de ser 
sujeito da sua própria história e possibilitando ao usuário cuidado no território, respeitando a sua vontade, o seu desejo em relação ao tempo de conseguir avançar ou de entender que uso de álcool e outras drogas tem trazido algum prejuízo do ponto de vista de sua própria saúde, das suas relações familiares, das relações comunitárias, de trabalho, dentre outros.

A partir disso, é elaborado um projeto terapêutico singular (PTS) em que diversos aspectos da sua vida são contemplados como a questão do seu acesso à saúde, a forma que se vai dar seu acompanhamento nesse dispositivo de saúde mental, quais são os outros serviços que ele precisa ser referenciado na saúde e em outras políticas sociais - quais as suas necessidades do ponto vista de seus direitos como os programas sociais necessários: se há a necessidade de acolhimento por estar em situação de rua, de orientação para expedição de segunda via de documentos que torna-se empecilho pelo fato de não tê-los, para inclusão em programas sociais ou no mercado de trabalho.

Quando o usuário assistido do CAPS AD está internado numa instituição e, consequentemente, fora do território e que se institui enquanto uma instituição total, na maioria das vezes, estes serviços não dispõem de equipe multiprofissional, o viés de atenção em geral é religioso e se direciona todo o "tratamento" na perspectiva da abstinência e do controle de comportamentos. Dessa forma, acaba lhe sendo negado o direito de respeito a subjetividade.

O trabalho da assistente social em Caps Ad é de extrema relevância, posto que esta profissional tem uma bagagem teórica e conhecimento da legislação que possibilita acionar a rede socioassistencial e intersetorial e constitui-se desta forma, em um agente importantíssimo que, junto com a equipe multiprofissional, pode viabilizar o acesso do usuário aos diversos dispositivos de cuidado de que ele necessita.

Além disso, a perspectiva moralizante a partir da qual, geralmente, esse sujeito é preconcebido, faz com que ele seja abordado e julgado nos diversos serviços como preguiçoso, violento, alcoólatra, viciado, dentre outros adjetivos e, não são raras vezes em que a assistente social precisa utilizar-se do conhecimento que tem sobre as legislações para garantir que o usuário tenha o seu direito de ser atendido respeitado. Com isso, trata-se não só de garantir o direito de atendimento imediato nos demais dispositivos da rede, como também, ao longo do tempo, trabalhar na desmistificação desta visão sobre estes usuários. Infelizmente, dentro dos próprios dispositivos de saúde mental tais visões estão presentes.

Não se trata de um trabalho simples e rápido, mas algo que precisa ser construído/reconstruído no seu cotidiano profissional. Trata-se de um processo que é externo, mas também interno, pois estamos tão imersos nessa sociedade capitalista que visa o lucro a qualquer medida, que o discurso do "trabalho dignificante", ou "que só é cidadão aquele que consome", pode ser reproduzido pelos próprios trabalhadores dos CAPS, nas nossas ações.

Desta forma, é preciso que estejamos atentos e disponíveis o tempo todo para avaliar o nosso exercício profissional, pois a depender da forma com que lidamos com os usuários, poderemos nós mesmos, violar seus direitos, que viabilizá-los.

Assim sendo, o exercício profissional da assistente social na atenção ao uso abusivo de álcool e outras drogas é riquíssimo, pois possibilita-nos apreender com maior clareza a forma como a sociedade capitalista pós-moderna produz cada vez mais novas expressões da questão social, acirra as que já existem e traz um quadro de desigualdades sociais tão alarmantes, em que uma grande maioria detém a maior parte da riqueza do mundo e grande parte da população não consegue ter o mínimo para sua subsistência. 
Nesse campo nos depararmos com aquele sujeito que parece não se encaixar nessa sociedade, os chamados descartáveis para o capital, ao passo que, muitas vezes não consegue inserir-se no mercado de trabalho, não tem documentos, não tem acesso à alimentação, à moradia, ao saneamento básico, ou seja, ao mínimo para sobreviver. E mediante situações tão aviltantes, o uso das substâncias torna-se algo adjetivo, como uma tentativa de anestesiamento diante de uma realidade social tão cruel, desumana e desagregadora.

\subsection{Desafios postos ao trabalho dos assistentes sociais na atualidade.}

O cenário atual marcado pela restrição dos direitos sociais e das políticas públicas, bem como, os retrocessos em voga na saúde mental tanto com a Nota Técnica nº11/2019 que instituiu, dentre outros, mudanças na Nova Política sobre Drogas ${ }^{2}$, e ainda, pela pandemia do Covid-19 tem-nos colocado vários desafios enquanto profissionais da saúde mental e do Serviço Social.

Dentre eles podemos apontar a necessidade de repensarmos o exercício profissional a partir das novas demandas que surgem no interior dos CAPS, bem como nas outras políticas sociais, precisando não os ver enquanto desvio de função, mas talvez como novos desafios postos à profissão. Costa (2006) discute bem essa questão, apontando que na medida em que o capitalismo e os modos de exploração se modificam, ocorre uma transformação na forma como as expressões da questão social se mostram na vida dos sujeitos e precisamos acompanhar e propor estratégias profissionais condizentes com esse novo cenário.

Outro desafio que é de extrema relevância e que a nosso ver não tem sido dada a devida importância, é referente à questão de gênero e de raça que permeia a questão de saúde mental e traz consequências para esses indivíduos. Exemplo disso, é que nos serviços de atenção psicossocial voltados para atendimento aos casos de álcool e outras drogas, a maior parte dos usuários ou daqueles que são criminalizados, são sujeitos pobres e negros.

Por conseguinte, o Serviço Social tem um débito neste âmbito, visto que as discussões até então existentes abordavam de modo bastante incipiente tais aspectos. Contudo, recentemente, este quadro vem se alterando de uma forma bastante potente e provocativa, com autores como Passos (2018) e Duarte (2017). Precisamos estar atentos a tais aspectos no cotidiano para garantir um exercício profissional que defenda a emancipação dos sujeitos e a luta contra qualquer forma de discriminação.

Além disso, o cenário atual da pandemia da Covid-19 já demonstra o agravamento da saúde mental da população por conta da necessidade do distanciamento social, como das perdas em decorrência do grande número de mortes, do cenário nacional de obscurantismo no que concerne às decisões políticas, o negacionismo diante da gravidade da pandemia e ainda, as consequências econômicas e sociais trazidas como o aumento do desemprego e da fome, a falta de perspectiva de melhora ou superação da pandemia, uma vez que não se tem uma posição política objetiva de defesa da importância da vacinação em massa, da implementação de políticas visando a melhoria das condições de acesso ao trabalho e aos bens para o consumo para as populações, sobretudo as mais pobres. O próprio auxilio emergencial, importante benefício

\footnotetext{
2 Com a substituição da lógica de redução de danos pela da abstinência e o privilegiamento do financiamento para as comunidades terapêuticas em detrimento do incentivo paras serviços na lógica da atenção psicossocial.
} 
eventual criado durante a pandemia, sofre retrocessos no que tange ao valor de redistribuição às famílias.

Todo este cenário tem relação intrínseca e impacta diretamente na profissão da assistente social visto que somos chamados a sermos não só executores das políticas sociais como afirmava Netto (1998), mas também a pensarmos na formulação de tais políticas para o enfrentamento dessas novas expressões da questão social.

$\mathrm{Na}$ saúde mental especificamente, a pandemia apontou a necessidade de reavaliarmos e reestruturarmos a rotina dos serviços e o atendimento aos usuários, dentro dos CAPS, na medida em que foram suspensas as atividades coletivas em seu interior, dada a necessidade de contenção da proliferação do vírus. Isso teve um impacto importante no cuidado com os usuários e tem deixado lacunas, pois o espaço de convivência dentro dos CAPS se constitui numa estratégia importantíssima para o tratamento do usuário com sofrimento mental, visto que é nele que exercitamos a sociabilidade dos sujeitos, que se constrói coletivamente ideias e decisões para o enfrentamento deste cenário adverso.

Além disso, o acentuado quadro de desigualdade social que vivemos no nosso país faz com que esses espaços de saúde mental sejam não apenas lugar de tratamento, mas também de acesso à alimentação pelos usuários e, em muitos casos, o único local, sobretudo no caso dos usuários que encontram-se em situação de rua.

Alicerçados nos princípios do código de ética profissional (1993), precisamos defender de forma intransigente a não interrupção do acompanhamento diário no CAPS e pensar estratégias que assegurem aos profissionais, aos usuários e seus familiares proteção; defender a inclusão desses sujeitos como prioritários para vacinação uma vez que, devido ao transtorno mental, podem ter dificuldade para utilizar os mecanismos disponíveis para evitar o contágio.

\section{Considerações finais}

Podemos afirmar que todo o trabalho da assistente social em CAPS perpassa na consolidação cotidiana do que Franco Rotelli (2001) chamou de desinstitucionalização, a partir da experiência da reforma psiquiátrica italiana e que foi adotada na reforma psiquiátrica brasileira.

Desinstitucionalizar implica não apenas a retirada dos usuários com transtornos mentais dos hospícios, mas se relaciona, sobretudo, com a desconstrução da ideia de que os usuários com transtornos mentais são objetos de intervenção das várias categorias profissionais presentes na saúde mental; refere-se à defesa intransigente de que eles são sujeitos de direitos e devem ter acesso ao cuidado em liberdade, no seu território, gozando da convivência familiar e comunitária. Refere-se ainda à desconstrução da compreensão estigmatizadora desses sujeitos enquanto cidadãos de menor valor ou desprovidos de razão, que é algo culturalmente construído. E este trabalho só possível no cotidiano, a partir da articulação do conhecimento teórico com posicionamento ético e político em favor dos direitos destes sujeitos e por espaços de cuidado democráticos, alicerçados nas premissas, majoritariamente defendidas em nossa profissão e no processo de reforma psiquiátrica de cunho emancipador.

Cabe ressaltar que, neste trabalho não trouxemos a discussão do exercício profissional do Serviço Social em CAPS, a partir apenas das atribuições privativas da profissional, mas para provocar a reflexão sobre o trabalho da assistente social enquanto parte do trabalho coletivo 
integrado com outros profissionais de modo interdisciplinar. Como dito por Machado (2008, p.54-55),

[...] a insterdisciplinaridade implica o entrelaçamento das diversas especialidades de saberes e práticas profissionais na construção de propostas de trabalho na perspectiva da integralidade, intersetorialidade e equidade, que contemple ou aproxime (ao máximo) as necessidades dos grupos e indivíduos em sua totalidade (...) exige-se que os profissionais trabalhem em equipe na lógica de interdependência e com plasticidade, o que significa reconhecer que seus conhecimentos específicos e suas práticas correspondem a uma parte dessa totalidade de trabalho coletivo.

Pode ser questionado em algum momento que muito do que fora dito sobre as ações da assistente social não se constitui algo específico ou privativo da profissão, e o queremos chamar atenção é justamente para este aspecto: que a assistente social dentro da Saúde Mental e dos CAPS, embasado na perspectiva do seu projeto político profissional e dos princípios do projeto da reforma psiquiátrica e sanitária, pode ter um papel de protagonismo na direção do trabalho dentro desses dispositivos de modo a assegurar e ampliar os direitos dos usuários e familiares da saúde mental.

\section{Referências}

ALMEIDA, W. da S. de et al. Mudanças nas condições socioeconômicas e de saúde dos brasileiros durante a pandemia de COVID-19. Revista Brasileira de Epidemiologia [online]. 2020, v. 23. Disponível em: https://doi.org/10.1590/1980-549720200105. ISSN 1980-5497. Acesso em: 11 jun. 2021.

AMARANTE, P. (Org) Saúde Mental - Políticas e instituições: Programa de Educação à distância. Rio de Janeiro: FIOTEC/FIOCRUZ, 2003.

AMARANTE, P. Saúde Mental e Atenção Psicossocial. Rio de Janeiro: Editora Fiocruz, 2007.

BRASIL. Ministério da Saúde. Secretaria de Atenção à Saúde. DAPE. Coordenação Geral de Saúde Mental. Reforma psiquiátrica e política de saúde mental no Brasil. Documento apresentado à Conferência Regional de Reforma dos Serviços de Saúde Mental: 15 anos depois de Caracas. OPAS. Brasília, novembro de 2005.

BRASIL. Ministério da Saúde. Secretaria de Atenção à Saúde. Portaria nº 3.088, de 23 de dezembro de 2011. Institui a rede de atenção psicossocial para pessoas com sofrimento ou transtorno mental e com necessidades decorrentes do uso de crack, álcool e outras drogas, no âmbito do Sistema Único de Saúde (SUS). Diário Oficial da União, Brasília. Edição n. 251, Seção 1, p. 59. 
BRASIL. Ministério da Saúde. Secretaria de Atenção à Saúde. Nota Técnica no 11/2019-. Esclarecimentos sobre as mudanças na Política Nacional de Saúde Mental e nas Diretrizes da Política Nacional sobre Drogas. Ministério da Saúde 2019;

BRASIL. Ministério da Saúde. Secretaria de Atenção à Saúde. Secretaria de Atenção à Saúde/DAPE. Saúde Mental no SUS: acesso ao tratamento e mudança do modelo de atenção. Relatório de Gestão 2003-2006. Ministério da Saúde: Brasília, 2007, 85p.

COSTA, M. D. H. da. O trabalho nos serviços de saúde e a inserção dos (as) assistentes sociais. In: MOTA, Ana Elizabete et al (Orgs.) Serviço Social e Sociedade. São Paulo: OPAS, OMS, Ministério da Saúde, 2006. p.304-351

DELGADO, P. G.G. As razões da tutela: psiquiatria, justiça e cidadania do louco no Brasil. Rio de Janeiro. Te Cora Editora, 1992.

DUARTE, M. J. de O. Diversidade sexual e de gênero e saúde mental: Enlaçando políticas e direitos. In: PASSOS, Rachel. Gouveia.; COSTA, Rosane de Albuquerque.; SILVA, Fernanda. Gonçalves da (Org.). Saúde mental e os desafios atuais da atenção psicossocial. Rio de Janeiro: Gramma, 2017.

GOFFMAN, (1961) Erving. Manicômios, prisões e conventos. 3. ed. São Paulo. Perspectiva, 1990.

IAMAMOTO, M. V. Serviço Social na Contemporaneidade: trabalho e formação profissional. 8. ed. São Paulo : Cortez editora, 2005.

KINOSHITA, R. T. Contratualidade e Reabilitação psicossocial. In: Reabilitação psicossocial no Brasil. PITTA, A. (org). São Paulo. Ed. Hucitec, 1996. p.55-59

MACHADO, G. S. Reforma Psiquiátrica e Serviço Social: o trabalho dos assistentes sociais nas equipes dos CAPS. In: Vasconcelos, E.M. (org) Abordagens Psicossociais. Volume III:

Perspectivas para o Serviço Social. São Paulo: Aderaldo \& Rothscild, Editora Hucitec, 2009. Cap 2. p.32-120.

MENDES, A. da S; OLIVEIRA, W. G. (2011). Pensando a integralidade do cuidado a partir do fluxo PSF/CAPS. Perspectivas Online: Humanas \& Sociais Aplicadas, 1(1). https://doi.org/10.25242/8876112011189

NETTO, J. P. Ditadura e Serviço Social: uma análise do Serviço Social no Brasil pós-64. 7. ed. São Paulo: Cortez, 2004.

MILLANI, H. de F. B; VALENTE, M. L. L. de C. O caminho da loucura e a transformação da assistência aos portadores de sofrimento mental. Revista Eletrônica Saúde Mental Álcool e Drogas. São Paulo, v.04, n.2, 01-19. 2008 
PASSOS, R. G. “Holocausto ou Navio Negreiro?”: inquietações para a Reforma Psiquiátrica brasileira. Argumentum, Vitória, v. 10, p.10-23, 2018

ROSA, L. C. S. A família como usuária de serviços e como sujeito político no processo de Reforma Psiquiátrica. In: Vasconcelos, E.M. (Org) Abordagens Psicossociais. Volume III: Perspectivas para o Serviço Social. São Paulo: Aderaldo \& Rothscild, Editora Hucitec, 2009. Cap 4. p.159-182.

ROTELLI, F. et al (orgs) Desinstitucionalização. São Paulo. Ed. Hucitec, 2. ed., 2001.

TENÓRIO, F. Breve Histórico da Reforma Psiquiátrica. In: A Psicanálise e a clínica da Reforma Psiquiátrica. Rio de Janeiro: Rios Ambiciosos, 2001. (cap. I)

VASCONCELOS, E. M. Abordagens Psicossociais. Volume I: História, teoria e trabalho no campo. São Paulo: Aderaldo \& Rothscild, Editora Hucitec, 2008. 209p.

VASCONCELOS, E. M. Proposta de atuação do serviço social no município do Rio de Janeiro. In: Vasconcelos, E.M. (org) Abordagens Psicossociais. Volume III: Perspectivas para o Serviço Social. São Paulo: Aderaldo \& Rothscild, Editora Hucitec, 2009. Cap 1.p. 25-31. 